\title{
A significação do problema didático a partir de Potenciais Problemas Significadores: análise de uma aula investigativa
}

\section{The meaning of a teaching problem according to Potentially Meaningful Problems: the analysis of an inquiry-based lesson}

\author{
Ana Paula Solino ${ }^{1}$ \\ https://orcid.org/0000-0003-4232-4516 \\ Lucia Helena Sasseron ${ }^{2}$ \\ https://orcid.org/0000-0001-5657-9590
}

\begin{abstract}
Resumo: Analisa-se a significação de um problema didático em atividade baseada no Ensino por Investigação. Para isso, buscou-se responder a seguinte questão: de que forma professora e alunos atribuem sentidos e significados a um problema didático trabalhado em aula investigativa? Metodologicamente realizou-se uma pesquisa qualitativa, com dados da videogravação de aula investigativa com alunos do $3^{\circ}$ ano do ensino fundamental de uma escola pública, posteriormente transcrita e organizada por episódios e cenas. O instrumento de análise foram os elementos significadores da noção de problema em Vigotski. Como resultado destaca-se que a resolução do problema didático pelos alunos teve campo amplo de significações para dar sentido ao problema, enfrentando tensões entre o pensamento cotidiano e o científico, essenciais para a emergência de Potenciais Problemas Significadores. Argumenta-se a favor de que os elementos significadores podem servir como ferramenta pedagógica e analítica para orientar e avaliar o processo de significação em aulas investigativas, a partir do surgimento de novos problemas.
\end{abstract}

Palavras-chave: Ensino de ciências. Ensino por investigação. Resolução de problemas. Significação de problemas. Ensino fundamental.

\begin{abstract}
This study analyzes the meaning of a teaching problem proposed in an inquiry-based activity. In order to do that, we tried to answer the following question: how do teacher and students assign meanings to and make sense of a teaching problem in an inquiry-based lesson? The qualitative study was carried out using data from the video recording of an investigative class, with students of the 3rd year of an elementary public school. The material was transcribed and organized into episodes and scenes. The instrument of analysis were the meaningful elements in Vygotsky's notion of problem. Findings underscore that the resolution of the teaching problem by the students was marked by a wide range of meanings to make sense of the problem. The students had to deal with tensions between every day and scientific thinking, which are essential for the emergence of PMP Potentially Meaningful Problems. It is argued that the meaningful elements can serve as pedagogical and analytical tools to guide and evaluate the process of signification in inquiry-based lessons, as new problems emerge.
\end{abstract}

Keywords: Science education. Inquiry-based teaching. Problem solving. Problem meaning. Elementary school.

\footnotetext{
${ }^{1}$ Universidade Federal de Alagoas (UFAL), campus do Sertão, Delmiro Gouveia, AL, Brasil.

E-mail: ana.bastos@delmiro.ufal.br

${ }^{2}$ Universidade de São Paulo (USP), Faculdade de Educação (FE), São Paulo, SP, Brasil.
} 


\section{Introdução}

Estudos sobre a importância do problema no ensino de ciências têm ocupado um espaço relevante na didática das ciências. A literatura sobre este tema tem sido bastante proeminente, e ao mesmo tempo complexa, porque abrange diferentes referenciais teóricos com propósitos e métodos de ensino variados (SILVA; BELTRÁN NÚÑEZ, 2002). Todavia, parece haver um consenso entre os pesquisadores da área sobre a necessidade de propor problemas para auxiliar na aprendizagem dos estudantes (CAPPECHI, 2013; CARVALHO, 2013; DELIZOICOV, 2005; GIL et al., 1992; SILVA; BELTRÁN NÚÑEZ; RAMALHO, 2001).

No âmbito das propostas centralizadas em problemas existem abordagens de ensino que vêm ganhando espaços tanto nos cursos de formação superior, quanto no ensino básico, a exemplo da Abordagem Temática Freireana (DELIZOICOV; ANGOTTI; PERNAMBUCO, 2011), Abordagem Ciência, Tecnologia e Sociedade (CTS) (SANTOS; MORTIMER, 2002), e o Ensino por Investigação (AZEVEDO, 2004; CARVALHO, 2011a, 2013; MUNFORD; LIMA, 2007). Em relação a esta última, a mesma tem sido apoiada por diferentes estudiosos e suas bases epistemológicas e pedagógicas podem variar a depender da perspectiva teórica adotada. Contudo, existem alguns aspectos nessa abordagem de ensino que são consensuais entre os pesquisadores, como o desenvolvimento de habilidades inerentes à atividade científica levantar hipóteses em torno de um problema, coletar e analisar dados, argumentar e construir modelos explicativos (ZÔMPERO; LABURÚ, 2011). Entre os exemplos de trabalhos nessa linha, destacam-se: Azevedo (2004), Carvalho (2011a, 2013), Munford e Lima (2007), Sá, Lima e Aguiar Jr (2011), e Sasseron (2013).

O interesse pelo estudo de atividades envolvendo a resolução de problemas sempre foi algo presente nas pesquisas desenvolvidas pelo grupo LaPEF (Laboratório de Pesquisa e Ensino de Física), da Universidade de São Paulo (USP), desde os anos 1990. Em decorrência das reflexões trazidas pelos diferentes pesquisadores do grupo ao longo do tempo, surgiu a necessidade de um aprofundamento teórico-metodológico sobre o papel das interações discursivas no processo de ensino-aprendizagem, sobretudo, no desenvolvimento da argumentação (CARVALHO, 2011b). Deste modo, as pesquisas passaram a privilegiar análises de discursos, ações, sentidos e significados que são produzidos e negociados nas interações entre professor e alunos, buscando compreender a aprendizagem a partir da análise dos processos sociais, especialmente das linguagens utilizadas em sala de aula (ver, por exemplo, CAPECCHI, 2004; FERRAZ, 2015; SASSERON, 2008).

A preocupação com a linguagem no ensino de ciências não deslocou o olhar dos pesquisadores do grupo LaPEF sobre a importância do problema nas atividades investigativas. No contexto da perspectiva histórico-cultural, em especial os estudos fundamentados em Vigotski (ver, por exemplo, GEHLEN, 2009; GEHLEN; DELIZOICOV, 2011, 2012; SOLINO, 2017), o problema, na sua dimensão pedagógica, passa a ser compreendido na complexidade das relações interpessoais que ocorrem na sala de aula. É com base nisso que buscamos, nesse estudo, investigar o processo de significação do problema em aulas investigativas e entendemos que as análises das interações discursivas e as práticas sociais podem nos dar indícios de como o professor e os alunos produzem e negociam sentidos e significados em um processo colaborativo, no qual diferentes perspectivas culturais se encontram e se transformam mutuamente.

É intenção nesta pesquisa investigar o movimento de significação de problemas em 
aulas baseadas no Ensino por Investigação à luz de algumas ideias vigotskianas. Para isso, procuramos responder a seguinte questão: De que forma, professora e alunos, atribuem sentidos e significados a um problema didático trabalhado em uma aula investigativa? Assim, torna-se importante analisar os processos discursivos entre os sujeitos, tendo como foco principal as relações entre o problema e a atribuição de sentidos e significados em sala de aula.

\section{A noção de problema no Ensino por Investigação e os Elementos Significadores}

O Ensino por Investigação é uma abordagem didática que objetiva desenvolver nos alunos a compreensão de conteúdos das ciências, sua natureza e relações com a tecnologia, sociedade e meio ambiente, por meio do enfrentamento e resolução de problemas (SASSERON, 2008). Há algum tempo tem sido considerada por muitos pesquisadores como uma proposta que possibilita inserir os alunos no contexto de uma cultura científica (CAPECCHI, 2004; CARVALHO, 2011a), uma vez que as práticas sociais das ciências (como levantar hipóteses, trabalhar em equipe, refletir sobre o problema e argumentar pontos de vistas) são desenvolvidas em sala de aula. No âmbito das práticas sociais há aquelas que também envolvem processos para além da cognição, como as práticas epistêmicas de propor, comunicar, avaliar e legitimar entendimentos. Estas, por sua vez, norteiam a forma como alunos e professor negociam, compreendem e compartilham determinados conhecimentos transformando o ambiente de sala de aula em comunidades de práticas (ver JIMÉNEZ-ALEIXANDRE; CRUJEIRAS, 2017; KELLY; LICONA, 2018, entre outros).

Quanto à natureza dos problemas abordados em aulas investigativas, estes possuem uma estreita relação com o propósito de alfabetizar cientificamente os alunos (SASSERON, 2008), uma vez que a sua dimensão conceitual, as quais se referem a problemas pautados em temas de ciências, estabelecem estreita conexão com a natureza que circunda a prática social de resolução do mesmo e seus impactos na sociedade. No âmbito das atividades organizadas em Sequências de Ensino Investigativas (SEI) (CARVALHO, 2013), é possível identificar dois tipos de problemas: os problemas didáticos (PD) e os novos problemas (NP) (SOLINO, 2017).

Os problemas didáticos (PD) são aqueles previamente elaborados e/ou selecionados pelo professor para trabalhar temas de ciências em sala de aula. Os PD têm como critério de seleção conteúdos de ciências, os quais são transformados em problemas a serem investigados pelos alunos. Eles podem ser experimentais ou teóricos (CARVALHO, 2013), assim como podem variar nos graus de abertura, podendo uns serem mais abertos e outros mais fechados, a depender do objetivo da atividade. É importante deixar claro que os problemas fechados não impedem que os alunos tenham liberdade intelectual ${ }^{3}$ para resolvê-los, pois o que garante a abertura da investigação não são os problemas escolhidos pelo professor, mas sim a forma como o professor encaminha tal processo, organizando o trabalho dos alunos com as

\footnotetext{
${ }^{3}$ Compreendemos que a ideia de liberdade intelectual não significa isentar o professor do seu papel de orientador durante a investigação do problema.
} 
hipóteses e os dados para que construam possíveis explicações sobre o fenômeno estudado.

Por outro lado, os novos problemas (NP) são aqueles que emergem durante o desenvolvimento da atividade, isto é, surgem na trama das relações estabelecidas em sala de aula entre professor-aluno, aluno-aluno e aluno-material didático.

Ao analisar atividades investigativas, Capechi (2013) argumenta que os problemas são construídos discursivamente, por meio de questionamentos realizados tanto pelos alunos quanto pelo professor. Deste modo, os NP estão fundamentados neste entendimento, uma vez que as questões construídas na trama da interação discursiva em sala de aula podem ser consideradas como novos problemas em potencial para significar o PD. Salienta-se que os novos problemas nascem em decorrência do enfrentamento do problema didático (PD) e, portanto, não devem ser confundidos com a forma que assumem o PD, pois não são planejados antecipadamente e nem sempre aparecem em forma de perguntas. Os NP podem se apresentar em forma de questões e/ou afirmações que explicitam/geram conflito como potencializadores para o pensamento e reflexão sobre o problema didático que está sendo enfrentado.

Ao partir do pressuposto de que os novos problemas podem potencializar o enfrentamento e resolução dos problemas didáticos trabalhados em atividades investigativas, busca-se analisar de que forma os alunos, na relação com o professor, atribuem sentidos e significados em sala de aula. Para compreender tal processo, respaldou-se em alguns aspectos da perspectiva vigotskiana, em especial a sua compreensão sobre o termo problema.

Estudos realizados por Gehlen (2009) e Gehlen e Delizoicov (2011, 2012) têm revelado que o entendimento do termo problema em Vigotski apresenta uma dimensão epistemológica e humanizadora, se aproximando dos problemas reais vivenciados pelos sujeitos. Os autores afirmam que essa noção de problema potencializa não apenas o desenvolvimento cognitivo dos alunos, mas também o seu processo de humanização, pois ao mesmo tempo em que se busca resolver o problema, também se possibilita transformá-lo. Com base nesses trabalhos, Solino (2017) propõe alguns elementos significadores que ajudam a caracterizar tais problemas, quais sejam: necessidade, contradição, colaboração e imaginação/criatividade. Para esta autora, os elementos significadores podem servir como uma importante ferramenta para analisar a qualidade do processo de significação de problemas conceituais em propostas que têm se apoiado nas ideias vigotskianas, a exemplo do Ensino por Investigação ${ }^{4}$. No Quadro 1 apresentamos as funções do problema didático abordado pelo Ensino por Investigação a partir dos elementos significadores.

\footnotetext{
${ }^{4}$ Cabe salientar que a noção de problema no Ensino por Investigação se diferencia da dimensão humanizadora vigotskiana, pois seus problemas estão direcionados para temas conceituais de ciências e não para temas reais, fruto de contradições sociais vivenciadas pelos estudantes. No entanto, compreendemos que os elementos significadores podem ajudar a significar os problemas conceituais trabalhados em sala de aula.
} 
Quadro 1 - Elementos Significadores nas relações com o Ensino por Investigação

\begin{tabular}{|l|l|}
\hline Necessidade & $\begin{array}{l}\text { inicialmente criada pelo professor a partir da apresentação do PD como objeto de } \\
\text { estudo. A necessidade é dependente do motivo que impulsiona a agir (problema) e } \\
\text { das ações (forma como o problema é resolvido em sala de aula). As necessidades } \\
\text { presentes em aulas investigativas são do tipo cognitivas e estão inclusas na } \\
\text { manifestação das contradições conceituais, nas ações colaborativas e nos processos } \\
\text { de criação. }\end{array}$ \\
\hline Contradição & $\begin{array}{l}\text { as contradições sociais e conceituais são manifestadas pelos sujeitos ao enfrentar } \\
\text { o PD e estas impulsionam a construção de novos conhecimentos. No Ensino por } \\
\text { Investigação, elas geralmente aparecem nas hipóteses construídas pelos alunos, } \\
\text { em forma de contradições conceituais. Essas contradições representam um } \\
\text { estado psíquico de dificuldade intelectual, criada a partir dos problemas didáticos, } \\
\text { relacionada a uma necessidade cognitiva de resolver o problema. }\end{array}$ \\
\hline $\begin{array}{l}\text { Imaginação/ } / \\
\text { criatividade }\end{array}$ & $\begin{array}{l}\text { situação criada ou imaginada pelos alunos que visa solucionar o PD. Pela imaginação } \\
\text { podemos perceber como as experiências imediatas das crianças estão sendo } \\
\text { ampliadas. No Ensino por Investigação, geralmente a imaginação ou criação surgem } \\
\text { como possibilidades de soluções para o PD. }\end{array}$ \\
\hline Colaboração & $\begin{array}{l}\text { a colaboração entre os sujeitos deve atuar na zona de desenvolvimento proximal } \\
\text { (VIGOTSKI, 2007) para que os estudantes a compreendam. No Ensino por } \\
\text { Investigação, a colaboração pode ocorrer no âmbito da colaboração didático- } \\
\text { pedagógica e no âmbito da colaboração epistêmica. As colaborações didático- } \\
\text { pedagógicas envolvem a organização do ensino, como: controlar o tempo, distribuir } \\
\text { a classe conforme a tarefa, perseguir o objetivo da atividade, formular o problema, } \\
\text { regular comportamentos, direcionar a atenção do aluno, gerenciar tensões. Já as } \\
\text { ações colaborativas epistêmicas envolvem a organização e desenvolvimento do } \\
\text { pensamento científico dos alunos, como: construir novos conhecimentos e dar novas } \\
\text { informações, apresentar novos pontos de vista; colocar as respostas dos alunos } \\
\text { em avaliação; levar os alunos a testarem suas hipóteses, explicitar contradições } \\
\text { conceituais; legitimar ideias). }\end{array}$ \\
\hline
\end{tabular}

Fonte: Solino (2017).

Conforme discutimos anteriormente, os problemas didáticos são significados em sala de aula a partir do surgimento de novos problemas construídos durante as interações entre professor-aluno, aluno-aluno e aluno-material didático. E esses novos problemas podem ser transformados em Potenciais Problemas Significadores (PPS) ao emergirem em sala de aula a partir das relações com o conjunto de elementos significadores. Deste modo, os novos problemas configurados como PPS surgem em decorrência da presença de elementos significadores e tem potencial para significar os problemas didáticos. Os PPS têm como mola propulsora as contradições, as quais podem ser manifestadas discursivamente a partir dos sentidos que os sujeitos atribuem ao objeto de conhecimento, neste caso, o problema didático. Ressalta-se que os PPS não se reduzem às contradições, pois são desencadeados a partir das relações qualitativas existentes entre as necessidades-contradições-colaborações-imaginações/criatividades. O termo potencial presente nos PPS sugere a ideia de que os novos problemas não têm uma estrutura acabada, pois estão sempre em movimento de construção e reconstrução ao longo 
da dinâmica de uma aula. Os PPS se mostram, portanto, em eventos dinamicamente em transformação com pessoas participando da atividade com outros.

Nesta pesquisa, compreende-se que os elementos significadores servem não só como ferramenta pedagógica, cujo papel principal seja mediar as relações entre os conhecimentos dos sujeitos (professor-aluno) e as relações sujeitos-objeto para significar o PD, mas também podem servir como uma ferramenta analítica para avaliar a qualidade da significação do PD. Essa qualidade implica investigar o desenvolvimento do pensamento dos alunos a partir da superação das suas contradições, bem como da elaboração de processos imaginativos para criar novas situações ou ideias, do atendimento às necessidades cognitivas e da qualidade das colaborações incentivadas especialmente pelo professor. Em outras palavras, não basta simplesmente que seja identificada a presença ou não de novos problemas no desenvolvimento da aula, é preciso buscar evidenciar a qualidade desses novos problemas, por meio dos elementos significadores.

\section{Aspectos metodológicos da pesquisa}

Esta pesquisa encontra-se respaldada em uma abordagem qualitativa (LÜDKE; ANDRÉ, 2013), pois buscamos analisar as ações e os discursos de alunos e professora, durante uma atividade investigativa realizada em sala de aula. Os resultados da pesquisa estão para além das descrições dos fatos, pois preocupamo-nos em discutir os processos pelos quais as ideias da professora e alunos são negociadas e significadas quando estas são mediadas por problemas didáticos. Além disso, essa pesquisa se configurou como um estudo de caso (YIN, 2010), uma vez que buscamos analisar intensivamente um contexto real específico da sala de aula, a partir de gravações em áudio e vídeos das aulas. Para garantir uma maior credibilidade à pesquisa, tais dados foram triangulados posteriormente com outros estudos que também utilizaram as mesmas informações, porém com enfoques distintos, a exemplo de Raboni (2013) e Freiberg (2015).

Cabe salientar que esse estudo faz parte de uma pesquisa mais ampla de doutorado da primeira autora (SOLINO, 2017), a qual foi organizada em duas etapas: a primeira, de caráter teórico, abrangeu as discussões sobre a dimensão pedagógica do problema em Vigotski, apresentada nos estudos de Gehlen (2009) e Gehlen e Delizoicov (2011, 2012) e suas contribuições para a análise do problema no ensino por investigação, com destaque para o papel e função na estruturação e implementação de Sequências de Ensino Investigativas (SEI). E a segunda, de caráter empírico, envolveu a análise do movimento de significação de um problema didático presente em uma SEI, trabalhada com alunos do ensino fundamental. Neste presente trabalho, será discutida essa segunda etapa.

Os dados dessa pesquisa correspondem à transcrição da videogravação de aulas de Ciências da Natureza, implementadas em uma Escola Municipal de Ensino Fundamental, localizada em um bairro periférico da cidade de São Paulo, SP. À época, a professora (sujeito da pesquisa) participava regularmente das atividades de um projeto de formação de professores e adotava em suas aulas o material didático disponibilizado pelo LaPEF/USP. Tal material didático é composto por várias atividades investigativas organizadas no formato de Sequências de Ensino Investigativas (SEI) e disponibilizadas na coleção Investigar e aprender ciências, da editora Sarandi, de autoria de Carvalho et al. (2011). As informações foram coletadas no segundo semestre de 2012, em uma turma do $3^{\circ}$ ano do Ensino Fundamental, na qual estudavam 33 
alunos, sendo 17 meninos e 16 meninas, com média de idade entre 9 e 10 anos. Nesta pesquisa, criamos nomes fictícios para os alunos, com o intuito de resguardar suas identidades. Cabe ainda ressaltar que os responsáveis pelas crianças e a professora autorizaram a gravação e o uso do material para a pesquisa, por meio do Termo de Consentimento Livre e Esclarecido (TCLE).

A Sequência de Ensino Investigativa (SEI) discutida nesta pesquisa foi planejada para os anos iniciais do ensino fundamental e está organizada com base no tema Navegação e meio ambiente, composta por 11 atividades. Esta SEI visa promover condições para o desenvolvimento da alfabetização científica dos alunos ao propor discussões sobre temas das ciências enfocando as dimensões sociais e ambientais associadas à navegação. Para fins de análise, dentre as 11 atividades presentes na SEI, escolhemos a atividade 1, denominada Desafio da travessia do rio, pelo motivo de a mesma ter apresentado significativas interações discursivas entre os sujeitos, as quais envolveram ambiguidades de ideias, conflitos, dúvidas, perguntas, que, a nosso ver, ajudaram a compreender substancialmente o processo de significação do problema didático. Essa atividade tem o propósito de introduzir noções de equilíbrio, peso e volume, além de desenvolver o raciocínio lógico dos alunos. No decorrer da sequência, outras atividades são propostas, tais como: atividades experimentais, textos de sistematização e análises de imagens para organizar os conceitos referentes à flutuação dos corpos; problematizações acerca dos impactos ambientais ocasionados pelos meios de transporte aquático; leitura e análise de dados em tabela a partir de um jogo entre presas e predadores, além de outros textos para sistematizar e organizar os conhecimentos dos alunos sobre os problemas ambientais e a navegação.

Os dados foram transcritos e organizados em turnos de falas entre a professora e os alunos e categorizados em 3 episódios, os quais foram construídos a partir dos principais momentos presentes no processo de significação do problema na aula investigada, quais sejam: (1) Apresentando o Problema Didático; (2) Enfrentando o Problema Didático e o Surgimento dos Potenciais Problemas Significadores: tensões entre a lógica cotidiana e a lógica científica; (3) Resolvendo o Problema Didático: a simulação. Por episódios, entende-se como "momentos extraídos de uma aula, onde fica evidente uma situação que queremos investigar" (CARVALHO, 2011b, p. 33). Em outras palavras, os episódios são fragmentos de aulas significativas para serem investigadas, as quais dependem exclusivamente do problema da pesquisa e do objetivo do pesquisador. A denominação de cada episódio foi elaborada considerando a característica mais marcante do momento da aula.

No contexto desse artigo discutiremos apenas o segundo episódio, uma vez que os Potenciais Problemas Significadores (PPS) surgem a partir desse momento. Tal episódio foi subdividido em cenas demarcadas pelos PPS que surgiam durante a aula. Por cenas entendemos como subdivisões dos episódios, as quais são importantes para dar sentido aos dados analisados (CARVALHO, 2011b). Ressalta-se que, para este trabalho, foi necessário realizar recortes, apresentando apenas algumas cenas como exemplos para discutir o processo de significação.

O problema didático (PD) apresentado aos alunos foi exposto na sala de aula por meio da projeção em slide, acompanhado do seguinte enunciado: Três homens querem atravessar um rio. O barco que possuem suporta no máximo $130 \mathrm{~kg}$. Eles "pesam" 60, 65 e 80 quilos. Como proceder para atravessar o rio, sem afundar o barco? A resolução deste PD ocorre quando os alunos admitem a possibilidade de o barco fazer várias viagens entre uma margem e outra, considerando a estabilidade do barco e a capacidade que o mesmo comporta. Para trabalhar melhor esta atividade, 
a professora organizou os alunos em grupos de 4 e 5 pessoas, a fim de que os mesmos pudessem pensar coletivamente sobre o problema.

\section{Episódio: Enfrentando o Problema Didático: tensões entre a lógica cotidiana e a lógica científica}

A característica principal deste episódio são as tensões vivenciadas pelos alunos durante a atribuição de sentidos e significados ao PD. Grande parte das proposições imaginadas por eles estão enquadradas no contexto de um pensamento situacional, isto é, eles utilizam da lógica cotidiana para enfrentar o problema didático, enquanto que a professora se esforça para que os alunos elaborem ideias com base na lógica científica. Os PPS emergem dessa tensão, sendo criados pelos alunos e/ou pela professora e retomados, quando necessários, ao longo da atividade. Este episódio é composto por 15 cenas, as quais elegemos cinco delas para serem discutidas neste trabalho, por apresentarem uma participação mais efetiva dos alunos na elaboração de PPS.

\section{Cena 1: E se tivesse alguém para ir, aí pegava a gente e levava, depois trazia e levava?}

Nesta cena podemos observar os primeiros passos encaminhados pelos alunos para enfrentar o PD. Inicialmente a professora vai a cada grupo e observa como os alunos planejam resolver o problema. A cada tentativa, ela percebe contradições presentes na maneira de pensar dos alunos, revelando a construção de um raciocínio bem próximo de uma lógica cotidiana, a exemplo de sinalizarem a possibilidade de um dos amigos empurrarem o barco; atravessarem o rio nadando e/ou por meio de cordas. Em virtude das contradições de ideias apresentadas por eles, a professora busca colaborar de forma pedagógica e epistêmica, escrevendo na lousa as seguintes orientações:

T-14: Professora: Então a gente tem que eliminar algumas ideias aí para vocês não
falarem novamente. Então é... Tem que ir no barco. Tem que ir para o outro lado no
barco. Então não pode ir de outra forma, tem que ser no barco. Uma outra coisa: o rio é
bem grande, então não dá para empurrar o barco de volta. Se fosse uma distância curti-
nha não precisava ir de barco, concorda? Então não dá para empurrar o barco de volta.

Compreendemos que essa colaboração é importante, porque, ao mesmo tempo em que a professora utiliza de recursos pedagógicos (como a escrita na lousa) para construir o cenário do PD, esta ação possibilita que os alunos reorganizem seus pensamentos, pois, neste momento, a mesma escreve o que precisa ser considerado durante a análise do problema didático: tem que ir para o outro lado no barco e o rio é bem grande. Com isto, a professora sugere eliminar ideias contraditórias à lógica científica de resolução do PD, tais como: empurrar o barco e ir nadando. Com base nessa colaboração, surge um novo problema colocado pela aluna Maria (turno 15), o qual foi qualificado como PPS, pois demarca um novo direcionamento do pensamento dos alunos ao enfrentarem o PD: 
T-15: Maria: E se tivesse alguém para ir, aí pegava a gente e levava, depois trazia e levava?

T-16: Professora: Sim, ó! Olha aqui o que a Maria falou, repete Maria.

T-17: Maria: Uma pessoa entrava no barco para pegar uma que está desse lado e levava [inaudível]

T-18: Professora: Ahãn...mas não tem essa pessoa, tem só três pessoas. As três estão desse lado aqui do rio, as três estão ali e tem que chegar do outro lado do rio. O barco tá parado ali, tá vazio. As três pessoas precisam atravessar, só que o barco suporta apenas 130 quilos. E cada um tem: 60, outro 65 e o outro, 80 quilos, tá? É isso que vocês têm que pensar [...]

Diante das colocações apresentadas pela professora, a aluna Maria imagina a possibilidade de inserir uma quarta pessoa na história do PD para ajudar os três amigos na travessia. Em sua proposição, a aluna parece sentir necessidade de problematizar a sua hipótese, colocando-a em teste para que seus colegas e a professora discutam e avaliem. Para se certificar de que todos ouviram sua ideia, a professora imediatamente pede para a aluna repeti-la, o que parece indicar que a mesma percebe a potencialidade deste novo problema significar o PD. Isso pode ser evidenciado na própria fala da professora quando explicita no turno 16: "Sim, ó! Olha aqui o que a Maria falou, repete Maria".

Embora esse PPS conduza os alunos a pensarem o PD sob um ponto de vista diferente daqueles até então colocados em sala de aula (ir nadando ou jogar uma corda), é importante ressaltar que ele não ajuda a resolver o problema no contexto da lógica científica esperada pela professora. Por isso, no turno 18, a professora reforça mais uma vez as condições que envolvem o PD sinalizando que, neste cenário, não há possibilidade de existir uma quarta pessoa. “Ahãn...mas não tem essa pessoa, tem só TRẾS pessoas. As três estão desse lado aqui do rio, as três estão ali e tem que chegar do outro lado do rio [...]."

Assim, nesta primeira cena, diferentes hipóteses foram formuladas pelos alunos, tais como: um dos amigos deve ir sozinho e empurrar o barco de volta para que os outros possam atravessar; atravessar nadando; incluir mais uma pessoa para ajudar na travessia dos três amigos. Entende-se que os alunos utilizaram da imaginação, das suas vivências e experiências para tentar resolver o problema, mas não obtiveram sucesso em suas proposições iniciais, pois a professora logo percebeu contradições de sentidos entre as ideias formuladas por eles em relação às ideias esperadas por ela. Cabe ressaltar que as ideias esperadas pela professora são aquelas condizentes com a lógica científica, a qual requer a elaboração de um raciocínio científico para analisá-lo (OSBORNE, 2016), diferente do pensamento cotidiano.

À medida que as hipóteses dos alunos foram sendo apresentadas, a professora parecia sentir necessidade de colaborar, ora reforçando-as positivamente, ora refutando-as, explicitando assim as contradições expressas nas ideias dos alunos. A colaboração da professora é do tipo epistêmica, porque seu intuito é orientar as ações dos estudantes, direcionando-os para a construção de um raciocínio mais próximo do científico, o qual envolve a mobilização de saberes mais elaborados. Essa colaboração apresenta consonância com as ideias de zona de desenvolvimento proximal (ZDP) de Vigotski (2007), que busca potencializar o desenvolvimento cognitivo dos alunos por meio da participação da professora, ao apontar os erros e direcionar novos caminhos. Para Vigotski (2009a), a ZDP pode ser entendida como a relação entre os processos 
maduros e os processos em maturação de um indivíduo. Em outras palavras, os processos maduros são aqueles encontrados na zona de desenvolvimento real do indivíduo, isto é, quando uma criança consegue resolver, sozinha, um determinado problema situado historicamente. $\mathrm{E}$ os processos em maturação são aquelas funções que potencialmente poderão vir a ser desenvolver, isto é, quando uma criança consegue resolver o problema, por meio da ajuda ou colaboração.

O PPS, portanto, apresentado pela aluna Maria no turno 15, embora também tenha se manifestado como uma contradição à lógica científica do PD foi, ainda assim, considerado como um potencial problema significador, porque foi colocado pela aluna de forma questionadora, como decorrência de suas necessidades cognitivas de enfrentar o PD.

\section{Cena 2: E se colocasse uma corda no barco? Um vai lá, vai o outro e puxa o barco?}

Em continuidade às discussões anteriores, nesta segunda cena evidenciou-se um novo problema, dessa vez colocado pelo aluno Fabrício, o qual qualificamos como PPS. Ele surge em decorrência do PPS apresentado na cena anterior. Imaginar que amarrar a corda no barco (para que um dos amigos que já atravessou possa puxar o barco do outro lado do rio) leva Fabrício, de forma semelhante à aluna Maria, a sentir necessidade de problematizar sua hipótese, colocando-a em teste para que todos possam discuti-la e avalia-la, pois o aluno parece perceber a potencialidade de a sua ideia significar o PD. No entanto, esse PPS não é valorizado pela professora de modo a ser discutido em sala de aula, pois a mesma o refuta imediatamente dizendo ao aluno que esta ideia não dá, porque não tem corda no cenário do PD. Ela busca fazê-lo recordar as condições de contorno que havia mencionado anteriormente na cena 1, ao questionar, no turno 20: “lembra que eu já falei??'. Sendo assim, embora o PPS apresentado pelo aluno Fabrício não tenha sido explorado pela professora, a mesma colabora ao recolocar as condições de contorno que foram debatidas na cena anterior, conforme é possível observar no diálogo abaixo:

T-19: Fabrício: Esecolocasse uma corda no barco? Um vai lá, vai o outro epuxa o barco? T-20: Professora: Não, essa ideia também não dá, porque não tem corda, só tem o barco e o rio é bem grande, lembra que eu já falei?

Percebemos novamente que os sentidos atribuídos pelos alunos ao PD encontram-se ainda muito próximos de uma lógica cotidiana, isto é, de um pensamento situacional, ao invés de conceitual. Isso pode ser explicado pelo fato de o problema didático colocado em discussão apresentar uma natureza que permite a construção de cenários típicos do dia a dia para solucioná-lo, como por exemplo: utilizar de cordas no barco, empurrar o barco ou atravessar o rio nadando. Além disso, Vigotski (2009a) explica que quando as crianças operam com conceitos espontâneos durante a resolução de um problema não há conscientização sobre o seu próprio pensamento, pois a sua atenção está totalmente voltada para o objeto de conhecimento (que, neste caso, é o problema didático), através da observação direta. Daí a importância de o professor, neste processo inicial de significação do PD, fazer os alunos tomarem consciência das suas ações a partir dos diálogos criados em sala de aula. 
$\mathrm{Na}$ perspectiva histórico-cultural, a linguagem ou as interações discursivas promovidas em sala de aula são cruciais na transformação do pensamento cotidiano para o pensamento conceitual ou científico e é, por esta razão, que se torna fundamental que a professora crie um ambiente dialógico entre os alunos para que haja desenvolvimento cognitivo. Vigotski (2007, p. 13) mostrou em seus estudos que "quanto mais complexa [for] a ação exigida pela situação e menos direta a sua solução, maior a importância que a fala adquire na operação como um todo". Assim, pode-se também dizer que isso remete à possibilidade de surgimento de novos PPS para organizar e direcionar as ações dos alunos em situações, cujo problema didático requer uma solução mediada. Portanto, as interações são decisivas para o surgimento de PPS, pois é por meio das falas dos sujeitos que esses são manifestados. Cabe ressaltar que embora o PPS, apresentado nesta cena, no turno 19, tenha se manifestado como contraditório à lógica científica do $\mathrm{PD}$, uma vez que colocar uma corda no barco não resolveria o problema didático, ainda assim possibilitou a construção de uma nova ideia formulada por outro aluno, ao imaginar ser possível que os três amigos atravessassem um de cada vez, o que deu origem à formulação de um terceiro PPS na cena a seguir.

\title{
Cena 3: Um de cada vez? Me explica melhor como é que é isso.
}

A terceira cena é iniciada com um PPS proposto pela professora, no momento em que solicita ao aluno Rodrigo que explique melhor a sua ideia colocada no turno 21, o qual propõe que as pessoas atravessem uma de cada vez. A professora questiona esta ideia no turno 22, o que parece indicar que a mesma reconheceu a potencialidade desta proposição significar o PD. Vejamos o fragmento abaixo:

\author{
T-21: Rodrigo: Vai um de cada vez... \\ T-22: Professora: Um de cada vez? Me explica melhor como é que é isso. \\ T-23: Rodrigo: Vai... [inaudível] \\ T-24: Professora: Peraí... Ó, ó... escuta isso! Fala bem alto o que você falou.
}

Aqui mais uma vez chama-se atenção para a ação colaborativa da professora, de caráter epistêmico, pois o seu intuito com este questionamento, foi fazer com que o aluno Rodrigo explorasse a sua ideia, levando-o a criar justificativas para explicar sua proposição. Contudo, sua resposta, apresentada no turno 23, apesar de ser inaudível, parece ter sido contrária à lógica científica de resolução do PD, pois suscitou o desencadeamento de um novo PPS colocado por um outro aluno na cena 4 , a seguir.

\section{Cena 4: Se for um de cada vez como é que vai trazer o barco de volta?}

O PPS explicitado pela professora na cena anterior, juntamente com a resposta contraditória apresentada por Rodrigo no turno 23 (ainda que inaudível), parece ter desencadeado, logo em seguida, um novo problema, dessa vez colocado pelo aluno Natan, o qual o configurou-se como PPS. Ao ouvir a proposição do seu colega Rodrigo, Natan parece ter compreendido a contradição presente na ideia dele, o que o levou a problematizar a situação, ao mencionar, no turno 25: "Se for um de cada vez. como é que vai trazer o barco de volta?". Esse novo problema apresentado por Natan foi reforçado pela professora ao repetir sua indagação, no turno 26. Vejamos os diálogos abaixo: 
T-25: Natan: Se for um de cada vez como é que vai trazer o barco de volta?

T-26: Professora: Se for um de cada vez, olha o que o Natan falou: se for um de cada vez, como é que ele vai trazer o barco de volta?

T-27: Maria: A não ser que fosse um navio.

T-28: Aluno $\mathrm{NI}^{5}$ : Só se for uma corda, só...

T-29: Professora: Não... A ideia da corda a gente já superou, lembra?

T-30: Aluno NI: [inaudível]

T-31: Professora: Ah...não tem motor não... [inaudível] mas mesmo que tiver motor, ué!

T-32: Maria: Não tem ninguém lá pra dirigir...

T-33: Professora: Entendeu? Mesmo que tenha, vai [inaudível]

Neste momento, tanto o aluno Natan quanto a professora colaboram de forma epistêmica, problematizando e legitimando a contradição da ideia manifestada na fala de Rodrigo (turno 23, da cena 3), o qual inicialmente propôs que a travessia pudesse ser realizada indo uma pessoa por vez.

Esse PPS apresentado por Natan também desencadeou a construção de novas hipóteses e imaginações para resolver o problema didático, porém tais criações continuavam alicerçadas no pensamento cotidiano ou situacional dos alunos, conforme podemos observar no turno 27, quando Maria, ao responder o PPS proposto por Natan, sinalizou a possibilidade de existência de um navio no lugar de um barco para resolver a travessia, assim como um outro aluno, no turno 28, traz à tona novamente o uso da corda para solucionar a situação.

Para Vigotski (2009b) a imaginação da criança se difere da imaginação de um adulto, porque a relação que ela estabelece com o meio não tem a complexidade, a precisão e a variedade que caracterizam o comportamento do adulto e que constituem fatores determinantes para a imaginação. Isto é, o caráter combinatório, requerido durante o processo imaginativo, segundo o autor, é na sua qualidade e variedade inferior em relação às combinações realizadas por um adulto, daí a razão da dificuldade manifestada pelos alunos, durante o enfrentamento do PD, de apresentarem uma proposição mais elaborada, próxima de um pensamento científico. É nesse sentido que o processo de escolarização se torna crucial para o desenvolvimento do raciocínio científico e um dos motores que pode favorecer a significação de problemas em aulas baseadas no Ensino por Investigação é o PPS, pois leva os alunos a duvidarem das suas próprias compreensões, impulsionando-os a racionar, a explicitar o pensamento, a justificar proposições e a corrigir concepções. Os conflitos apresentados em sala de aula no formato de PPS não têm como função apenas criar um estado psicológico de desequilíbrio intelectual nos estudantes, mas também propiciar um distanciamento epistemológico do aluno em relação ao objeto de conhecimento (neste caso, o PD), o que pode favorecer a reestruturação das suas proposições imediatas. Deixemos claro que tal distanciamento epistemológico em relação ao problema didático não ocorre de forma rápida assim que o PPS é manifestado. É preciso que se dê tempo para que os alunos possam refletir melhor sobre as suas concepções.

\footnotetext{
${ }^{5}$ Aluno não identificado.
} 


\section{Cena 5: Então como vai chegar do outro lado?}

Em continuidade às discussões anteriores e principalmente após o PPS ter sido colocado pelo aluno Natan, no turno 25 da cena 4, os estudantes parecem se encontrar diante de um conflito. Isso fica claro na fala de um aluno, ao explicitar: "então como vai chegar do outro lado?" (turno 34). Esse novo problema também foi considerado um PPS, porque possibilitou uma nova reflexão e o replanejamento de novas ações para resolver o PD. No turno 35, a professora repete o PPS apresentado pelo aluno, compartilhando com toda turma e deixando claro que este é o problema central, conforme é possível observar no diálogo abaixo:

\section{T-34: Aluno NI: Então como vai chegar do outro lado?}

T-35: Professora: Então essa que é a pergunta: como é que vai chegar do outro lado?

Fabrício parece entender o dilema vivenciado pelo seu colega e propõe uma ideia diferente, colaborando com uma nova maneira de olhar o PD. Ele parece imaginar uma solução mais próxima da lógica científica e sua ideia demarca uma nova orientação ao objeto de conhecimento. Sua fala fica mais clara no turno 40, ao propor que "um dos amigos vai, deixa um lá. Pega o outro e volta”. A situação imaginada pelo aluno é coerente com a solução lógica do PD e, por isso, no turno 39, a professora reforça positivamente a sua ideia, chamando atenção da turma para uma análise compartilhada. No turno 41, ela relembra as condições importantes que norteiam o PD, como a capacidade que o barco comporta e o peso das três pessoas.

\section{T-39: Professora: Muito bem! Essa ideia do Fabrício é legal. Fala de novo mais alto. Presta atenção para ver se vocês concordam com ele. \\ T-40: Fabrício: Um dos amigos vai, deixa um lá. Pega o outro e volta. \\ T-41: Professora: Sim, isso é legal, só que você tem que pensar numa coisa: o barco só comporta 130 quilos. E ai um tem 60, o outro tem 65 e outro tem 80 quilos.}

A contribuição de Natan, ao problematizar ("então como vai chegar do outro lado?" - turno 34) foi crucial para provocar mudanças na forma de enfrentar o PD pelos seus colegas. Até então, as proposições apresentadas por eles estavam orientadas para fora do contexto científico do PD e, por meio dos PPS, em especial deste último, surgiram novas ideias que contribuíram para enquadrar o PD na sua lógica de resolução, esperada pela professora. É exatamente a partir desse momento que os alunos começam a enfrentar o PD, analisando-o sob a lógica científica.

\footnotetext{
T-44: Diego: Então, vai dois num barco só, um de 60 e 65... [inaudível] T-45: Professora: Peraí, peraí!!! Tá, entendi o que você quis dizer. Ele falou assim que vai dois: um de 80 e um de 65. Eu quero saber se vai dar certo... T-46: Diego: ... não! 60 e 65... porque senão não dá certo! T-47: Maria: $O$ de 65 precisa ir primeiro...
}

No turno 44, o aluno Diego imagina uma nova situação e propõe que as duas pessoas de 60 e 65 atravessem juntas. Ele contribui ao analisar o problema didático trazendo os dados, porém não conclui a solução. Preocupada em gerenciar os conflitos na sala de aula, a 
professora parece não ter escutado muito bem a ideia de Diego, e reformula sua fala de modo diferente daquela proposta pelo aluno. No entanto, Diego imediatamente corrige a professora, demonstrando ter assimilado a contradição presente na fala da mesma, ao dizer: "não! 60 e 65 ... porque senão não dá certo?'. Maria parece complementar o argumento de Diego ao enfatizar que o de 65 deve ir primeiro e não o de 80, como fora reformulado de forma equivocada pela professora no turno 45. As proposições de Diego e Maria levam a professora a formular um novo PPS nas cenas posteriores e as dificuldades apresentadas pelos alunos de caráter procedimental (relativas ao como resolver o PD) redirecionam as ações da professora, com o intuito de ajudá-los a pensar agora não somente no como solucionar, mas no porquê alguns procedimentos podem ou não ser realizados, por exemplo: "O de 60 e 65 eles podem ir juntos no barco? [...] Por que?"

Embora os alunos pareçam ter se esforçado a buscar analisar o PD no contexto da lógica científica, cenas posteriores revelam que os alunos começam a retomar ideias que anteriormente já haviam sido refutadas (tais como: empurra o barco, joga uma corda, vai nadando, coloca o gordinho de 80 quilos para emagrecer). Com isso, a professora busca novamente trazer os PPS colocados por ela mesma em cenas anteriores, com o intuito de encaminhar e manter o pensamento dos alunos na base da lógica científica, fazendo-os recordarem das condições de contorno que envolvem o problema didático. Tal fato pode ser observado nas diferentes questões levantadas pela professora em vários momentos da aula: "O que vocês acham, ó?! Vai o de 60 ou o de 65? [...] E aí, quem é que volta?"; "E o de 60 com o de 80, eles podem estar no barco os dois? [...] Então, como é que a gente vai fazer?"; "Perai, o de 80 pode buscar o de 60?"; "E aí, como é que a gente vai fazer? [...] Ó, quem é que pode ir primeiro?’.

Mesmo com a retomada desses PPS pela professora, os alunos enfrentaram algumas dificuldades com o problema e, em cenas posteriores, parecem não querer mais participar da aula, resistindo a colocar suas proposições. Isso evidencia uma situação conflituosa e preocupante para a professora, uma vez que a sua colaboração passa a ser repetitiva e em alguns momentos pouco produtiva, pois não tem propiciado o desenvolvimento de novas formas de pensar, visto que os alunos apresentavam limitações para avançar na análise do PD. Como consequência disso, os alunos apresentavam-se insatisfeitos em relação às suas ações na atividade, com afirmações do tipo: está difícil, eu não sei, não vai dar certo, o que parece revelar uma desmotivação em relação às tentativas fracassadas de enfrentar o PD.

Cabe ressaltar que, para a perspectiva histórico-cultural, esses conflitos gerados a partir da dificuldade em resolver o problema, nem sempre são ruins. Braga (2010) explica que a colaboração do professor durante o processo de atribuição de sentidos e significados em sala de aula também pressupõe gerar momentos de tensão e conflitos, os quais podem auxiliar no desenvolvimento intelectual dos alunos, ajudando-os a entenderem que as relações sociais são dramáticas e fazem parte da existência humana.

Assim, podemos dizer que as dificuldades encontradas pelos alunos no decorrer do enfrentamento do PD são importantes, pois podem ajudá-los a perceber que, em situações diversas do dia a dia, nem sempre é possível resolver os problemas facilmente. Além disso, podem também contribuir para reduzir a ansiedade dos mesmos, a qual muitas vezes os impedem de fazer uma análise cuidadosa do problema, recorrendo à estratégia de solução baseada apenas na tentativa e erro, sem uma reflexão crítica sobre a situação. Porém, ressaltamos que nesses momentos de conflitos e dificuldades é necessário que o professor esteja atento para 
que os níveis de envolvimento e motivação dos alunos não sejam reduzidos. E ao perceber a crescente dificuldade de os alunos atribuírem novos significados ao PD, a professora muda de estratégia e propõe uma simulação em sala de aula, convidando-os a dramatizarem o problema didático. Essa dramatização ocorreu da seguinte forma: três alunos foram escolhidos aleatoriamente pela professora para representarem os três amigos da história. Os três foram posicionados igualmente à frente da sala de aula e à medida que a professora lia novamente o enunciado do problema, perguntava para toda a classe: quem deve irprimeiro?; e depois; alguém volta?; pode voltar sożinho? A partir das respostas da classe, os três alunos iam simulando a travessia até alcançar o outro lado da sala de aula e essa estratégia os ajudaram a resolverem o problema.

A possibilidade de visualizar e concretizar o PD por meio da simulação ajudou os alunos a organizarem o raciocínio científico, superando o desejo e a necessidade de criar ideias ou imaginações fundadas apenas no seu contexto situacional ou cotidiano, fora da lógica científica de resolução do problema. Cabe ainda salientar que o desejo em alavancar o raciocínio científico dos alunos pela professora, por meio da estratégia da simulação, permitiu a presença de PPS, o qual foi desencadeado pela necessidade de ensinar da mesma em resposta às necessidades cognitivas requeridas pelos alunos durante o enfrentamento do PD.

O sucesso dessa estratégia pode ser explicado pelo fato de que os alunos do ensino fundamental necessitam de bases mais concretas para resolver um determinado problema didático que exige pensamento abstrato, como é o caso do PD proposto nesta aula. Vigotski (2009a, p. 152) destaca que o processo da formação de conceitos, especialmente para a criança, "está vinculado ao material sensorial de cuja percepção e elaboração ele surge", sendo assim, foi preciso que a professora materializasse o problema didático em forma de uma dramatização, para que a situação envolvida no PD fosse mais bem percebida por eles e mais bem analisada. Ainda segundo seus estudos, Vigotski (2009a) sempre sinalizou que uma criança é capaz de compreender o problema e o objetivo colocado na tarefa de igual maneira que um adulto, porém as formas de pensamento que ela utiliza para solucioná-lo se diferenciam daquelas utilizadas pelo adulto, uma vez que as suas funções mentais superiores se encontram em processo de desenvolvimento. Daí podemos explicar a origem das tensões e conflitos provocados pelo $\mathrm{PD}$, aspecto que nos leva a afirmar que este problema didático se apresentou bastante coerente com a zona de desenvolvimento proximal dos alunos do $3^{\circ}$ ano do ensino fundamental, tendo em vista que o seu enfrentamento e resolução dependeu de processos colaborativos da professora, demandando esforços cognitivos diferentes daqueles que são facilmente solucionados por ações imediatas realizadas pelos alunos. Ficou claro também que as interações verbais entre os sujeitos (alunos e professora) ajudaram a ajustar o significado dentro de um campo vasto de sentidos pessoais e o papel da professora no direcionamento desses sentidos foi essencial, visto que o seu propósito é de ensinar os alunos a pensar cientificamente e não de deixá-los totalmente livres para conduzir o problema didático da forma como desejarem. $\mathrm{Na}$ perspectiva histórico-cultural, o direcionamento das ações dos alunos pelo professor é fundamental e caso isso não tivesse acontecido os alunos poderiam até resolver o PD utilizando suas ideias pautadas no pensamento cotidiano, mas possivelmente, não teriam desenvolvido novas funções mentais superiores, isto é, novas formas de pensar para além daquelas cotidianamente aprendidas em situações que não exigem reflexões sofisticadas. 


\section{Considerações}

Nesta aula baseada no Ensino por Investigação, foi possível observar que durante o processo de significação da atividade Desafio da travessia do rio os alunos e a professora percorreram a um campo amplo de significações para dar sentido ao problema, enfrentando tensões entre o pensamento cotidiano e o científico, as quais foram essenciais para a emergência de PPS. Nesta aula, os PPS se manifestaram por meio de perguntas problematizadoras, no sentido apresentado por Capecchi (2013), as quais explicitaram/geraram conflito para que os alunos pensassem e refletissem sobre o PD apresentado.

A partir desse estudo, entendemos que o problema comumente formulado em aulas investigativas de ciências, por si só não garante a atribuição de sentidos e significados pelos alunos. É necessário que o mesmo seja negociado entre os sujeitos de modo a explicitar as contradições conceituais presentes nele, a partir das necessidades cognitivas e das vivências dos estudantes. Isso, porque o problema quando trabalhado em sala de aula, passa a ser reconstruído pelos alunos e pela professora a partir dos sentidos e significados atribuídos por eles. Assim, os PPS, portanto, vão se constituindo numa certa lógica de produção, coletivamente orientada e organizada pela professora e, nesse movimento de significação, determinados sentidos são colocados como verdadeiros, se impondo em relação a outros, uma vez que a ação da professora está voltada para o ensino de determinados conhecimentos científicos que estão para além daqueles produzidos no cotidiano.

Todavia, compreendemos ser necessário que as informações que constituem o cenário ou o contexto do PD não sejam inicialmente trazidas pelo professor, mas sim construída coletivamente em sala de aula, para que se crie um ambiente propício para o surgimento de PPS. Além disso, observamos que os PPS surgem no contexto de uma atividade de ensino que tenha como núcleo central um PD situado na zona de desenvolvimento proximal dos estudantes. Desta forma, não basta criarmos um ambiente de aprendizagem interativa, é necessário que durante o planejamento e estruturação da atividade baseada no Ensino por Investigação, levemos em consideração a qualidade do PD formulado, certificando que este problema não seja apenas um simples exercício, que pode ser resolvido a partir de estratégias e conhecimentos já apropriados pelos alunos, mas sim um problema que gere dúvidas, inquietações, questionamentos, conflitos e tensões, ou seja, um problema que gere necessidades cognitivas e colaborativas decorrentes das contradições, bem como gere processos imaginativos/criativos para resolvê-los.

Contudo, argumenta-se a favor de que os elementos significadores (necessidades-contradições-colaborações-imaginações/criatividades) que constituem os PPS podem servir como uma interessante ferramenta pedagógica e analítica para o professor orientar e avaliar o processo de significação em aulas baseadas no Ensino por Investigação a partir do surgimento de novos problemas. Entretanto, faz-se necessário ampliar as discussões desses elementos para além do contexto das interações em sala de aula, investigando seus limites e potencialidades na estruturação curricular de atividades didático-pedagógicas de ciências na dimensão humanizadora de Vigotski. 
A significação do problema didático ...

\section{Agradecimentos}

Agradecemos imensamente o apoio da Profa. Dra. Anna Maria Pessoa de Carvalho durante o desenvolvimento desta pesquisa. Agradecemos também ao apoio financeiro da Fundação de Apoio à Universidade de São Paulo (FUSP).

\section{Referências}

AZEVEDO, M. C. P. S. Ensino de ciências por investigação: problematizando as atividades em sala de aula. In: CARVALHO, A. M. P. (org.). Ensino de ciências: unindo a pesquisa e a prática. São Paulo: Thomson, 2004. p. 19-34.

BRAGA, E. S. Tensões eu/outro: na memória, no sujeito, na escola. In: SMOLKA, A. L. B.; NOGUEIRA, A. L. H. (org.). Questões de desenvolvimento humano: práticas e sentidos. Campinas: Mercado de Letras, 2010. p. 151-170.

CAPECCHI, M. C. V. M. Aspectos da cultura científica em atividades de experimentação nas aulas de física. 2004. Tese (Doutorado em Educação) - Faculdade de Educação, Universidade de São Paulo, São Paulo, 2004.

CAPECCHI, M. C. V. M. Problematização no ensino de ciências. In: CARVALHO, A. M. P. (org.). Ensino de ciências por investigação: condições para implementação em sala de aula. São Paulo: Cengage Learning, 2013. p. 21-40.

CARVALHO, A. M. P. O ensino de ciências e a proposição de sequencias de ensino investigativas. In: CARVALHO, A. M. P. (org.). Ensino de ciências por investigação: condições para implementação em sala de aula. São Paulo: Cengage Learning, 2013. p. 1-20.

CARVALHO, A. M. P. Ensino e aprendizagem de ciências: referenciais teóricos e dados empíricos das sequências de ensino investigativo (SEI). In: LONGHINI, M. D. (org.). O uno e o diverso na educação. Uberlândia: EDUFU, 2011a. p. 253-266.

CARVALHO, A. M. P. Uma metodologia de pesquisa para estudar os processos de ensino e aprendizagem em salas de aula. In: SANTOS, F. M. T.; GRECA, I. M. (org.). A pesquisa em ensino de ciências no Brasil e suas metodologias. 2. ed. rev. Ijuí: Unijuí, 2011b. p. 13-47.

CARVALHO, A. M. P.; OLIVEIRA, C.; SASSERON, L. H.; SEDANO, L.; BATISTONI, M. Investigar e aprender ciências: $4^{\circ}$ ano. São Paulo: Sarandi, 2011.

DELIZOICOV, D. Problemas e problematizações. In: PIETROCOLA, M. (org.). Ensino de física: conteúdo, metodologia e epistemologia em uma concepção integradora. 2. ed. Florianópolis: Editora da UFSC, 2005. p. 1125-150.

DELIZOICOV, D.; ANGOTTI, J. A.; PERNAMBUCO, M. M. Ensino de ciências: fundamentos e métodos. 4. ed. São Paulo, Cortez, 2011.

FERRAZ, A. T. Propósitos epistêmicos para a promoção da argumentação em aulas investigativas de física. 2015. Dissertação (Mestrado em Ensino de Física) - Universidade de São Paulo, São Paulo, 2015. 
FREIBERG, H. L. Elementos catalisadores para a promoção da negociação de sentidos. 2015. Dissertação (Mestrado em Educação) - Faculdade de Educação, Universidade de São Paulo, São Paulo, 2015.

GEHLEN, S. T. A função do problema no processo de ensino aprendizagem de ciências: contribuições de Freire e Vigotski. 2009. Tese (Doutorado em Educação Científica e Tecnológica) - Universidade Federal de Santa Catarina, Florianópolis, 2009.

GEHLEN, S. T.; DELIZOICOV, D. A dimensão epistemológica da noção de problema na obra de Vygotsky: implicações no ensino de ciências. Investigações em Ensino de Ciências, Porto Alegre, v. 17, n. 1, 2012, p. 59-79. Disponível em: http://www.if.ufrgs.br/ ienci/artigos/Artigo_ID279/v17_n1_a2012.pdf. Acesso em: 24 ago. 2015.

GEHLEN, S. T.; DELIZOICOV, D. A função do problema na educação em ciências: estudos baseados na perspectiva vygotskyana. Revista Brasileira de Pesquisa em Educação em Ciências, Belo Horizonte, v. 11, n. 3, 2011, p. 123-144.

GIL, D.; MARTINEZ TORREGROSA, J.; RAMÍREZ, L.; CARRÉE, A. D.; GOFARD, M.; CARVALHO, A. M. P. Questionando a didática de resolução de problemas: elaboração de um modelo alternativo. Caderno Catarinense de Ensino de Física, Florianópolis, v. 9, n. 1, p. 7-19, 1992.

JIMÉNEZ-ALEIXANDRE, M. P.; CRUJEIRAS, B. Epistemic practices and scientific practices in science education. In: TABER, K. S.; AKPAN, B. (ed.). Science education: an international course companion. Rotterdam: Sense Publishers, 2017. p. 69-80. DOI: https:// doi.org/10.1007/978-94-6300-749-8_5.

KELLY, G. J.; LICONA, P. Epistemic practices and science education. In: MATTHEWS, M. R. (ed.). History, philosophy and science teaching: new perspectives. Cham: Springer, 2018. p. 139-165. DOI: https://doi.org/10.1007/978-3-319-62616-1.

LÜDKE, M.; ANDRÉ, M. Pesquisa em educação: abordagens qualitativas. 2. ed. São Paulo: EPU, 2013.

MUNFORD, D.; LIMA, M. E. C. C. Ensinar ciências por investigação: em quê estamos de acordo? Ensaio, Belo Horizonte, v. 9, n. 1, p. 89-111, 2007. Disponível em: http://www. scielo.br/pdf/epec/v9n1/1983-2117-epec-9-01-00089.pdf. Acesso em: 30 mar. 2017.

OSBORNE, J. Defining a knowledge base for reasoning in science: the role of procedural and epistemic knowledge. In: DUSCHL, R. A.; BISMARCK, A. S. (ed.). Reconceptualizing STEM education: the central role of practices. New York: Routledge, 2016. p. 215-231.

RABONI, P. C. A. Solução de problemas experimentais em aulas de ciências nos anos iniciais do ensino fundamental e o uso da linguagem cotidiana na construção do conhecimento científico. 2013. Relatório (Pós-Doutorado) - Faculdade de Educação, Universidade de São Paulo, 2013. 
SÁ, E. F.; LIMA; M. E. C. C.; AGUIAR JR., O. A. A construção de sentidos para o termo ensino por investigação no contexto de um curso de formação. Investigações em Ensino de Ciências, Porto Alegre, v. 16, n. 1, p. 79-102, 2011. Disponível em: https://www.if.ufrgs. br/cref/ojs/index.php/ienci/article/view/247. Acesso em: 4. abr. 2017.

SANTOS, W. P.; MORTIMER, E. F. Uma análise de pressupostos teóricos da abordagem CTS (ciência-tecnologia-sociedade) no contexto da educação brasileira. Ensaio, Belo Horizonte, v. 2, n. 2, p. 133-162, 2002.

SASSERON, L. H. Alfabetização científica no ensino fundamental: estrutura e indicadores deste processo em sala de aula. 2008. Tese (Doutorado em Educação) Faculdade de Educação, Universidade de São Paulo, São Paulo, 2008.

SASSERON, L. H. Interações discursivas e investigação em sala de aula: o papel do professor. In: CARVALHO, A. M. P. (org.). Ensino de ciências por investigação: condições para implementação em sala de aula. São Paulo: Cengage Learning, 2013. p. 41-62.

SILVA, S. F.; BELTRÁN NÚÑEZ, I. O ensino por problemas e trabalho experimental dos estudantes: reflexões teórico-metodológicas. Química Nova, São Paulo, v. 25, n. 6B, p. 1197-1203, 2002. Disponível em: http://quimicanova.sbq.org.br/imagebank/pdf/ Vol25No6B_1197_22.pdf. Acesso em: 4 mar. 2017.

SILVA, S. F.; BELTRÁN NÚÑEZ, I.; RAMALHO, B. L. O pensamento do professor: o trabalho com problemas no ensino de ciências. In: ENCONTRO NACIONAL DE PESQUISA EM EDUCAÇÃO EM CIÊNCIAS, 3., 2001, Atibaia. [Anais...] Atibaia: ABRAPEC, 2001.

SOLINO, A. P. Potenciais problemas significadores em aulas investigativas: contribuições da perspectiva histórico-cultural. 2017. Tese (Doutorado em Educação) Faculdade de Educação, Universidade de São Paulo, São Paul, 2017.

VIGOTSKI, L. S. A construção do pensamento e da linguagem. 2. ed. São Paulo: Martins Fontes, 2009a.

VIGOTSKI, L. S. A formação social da mente. 7. ed. São Paulo: Martins Fontes, 2007. VIGOTSKI, L. S. Imaginação e criação na infância. São Paulo: Ática, 2009b.

YIN, R. K. Estudo de caso: planejamento e métodos. 4. ed. Porto Alegre: Bookman, 2010. ZÔMPERO, A. F.; LABURÚ, C. E. Atividades investigativas no ensino de ciências: aspectos históricos e diferentes abordagens. Ensaio, Belo Horizonte, v. 13, n. 3, p. 67-80, 2011. Disponível em: http://www.scielo.br/pdf/epec/v13n3/1983-2117-epec-13-03-00067.pdf. Acesso em: 5 jun. 2015.

Submetido em: 12/06/2018. Aceito em: 15/03/2019

Contato: Universidade Federal de Alagoas, campus do Sertão, Delmiro Gouveia, AL, Brasil. 
